\title{
Software for the Design of Swimming Pool Dehumidifiers Units
}

\author{
Aleš Rubina, Petr Blasinski, Zdeněk Tesař \\ Department of building services \\ Brno University of technology, Faculty of civil engineering \\ E-mail: rubina.a@fce.vutbr.cz
}

\begin{abstract}
The article deals with the description and solution of physical phenomena taking place during evaporation of water. The topicality of the theme is given a number of built indoor swimming pool and wellness centers at present. In addressing HVAC systems serving these areas, it is necessary to know the various design parameters in the interior including the water temperature as the pool temperature and humidity. Following is a description of the calculation module, air handling units, including optimizing the settings of the physical changes in order to ensure the lowest energy consumption for air treatment and required maintaining internal microclimate parameters.
\end{abstract}

Key words: air-conditioning, evaporation from water surface, dehumidification of swimming pools, software development

\section{Introduction}

When we design the ventilation systems serving areas of swimming pools, indoor water surfaces and wellness technologies it is necessary to determine the mass flow of evaporating water and the heat flows from wet surfaces or water levels uncovered reservoirs. Evaporation involves the transfer of heat and moisture (mass), both processes simultaneously affect the thermodynamic state of air over these surfaces. For these cases was on the department of building services Faculty of civil engineering of Brno VUT created a new software module for TERUNA called "pools", which research on modelling of physical phenomena.

\section{The theory of moisture transfer}

Moisture transfer is one of the kinds of transfer phenomena, which is part of the air transferred substance - mostly water vapour, generally gaseous impurities. This occurs by two mechanisms, namely:

a) oscillating of particles - this is the random motion of molecules (diffusion) 
b) volume, the macroscopic fluid motion - a large mass of the molecules at any time move collectively in large volumes (advection)

The result of superposition of these mechanisms leads to mass transfer due to convection. The default solution for this phenomenon is to determine the diffusion of water vapour. Mass density of fluid flow in the stationary diffusion between points with different concentrations (for isothermal happening), or different partial pressures (generally valid) represented by Fick's law:

$$
J_{m}=-D_{C} \cdot \frac{\partial c}{\partial n}=-D_{D} \cdot \frac{\partial p}{\partial n} \quad\left[\mathrm{~kg} /\left(\mathrm{m}^{2} \cdot \mathrm{s}\right)\right]
$$

where, $c$.... concentration of diffusing substance $\left[\mathrm{kg} / \mathrm{m}^{3}\right]$

$n . .$. length in the direction normal to isobar or lines with a specific concentration $[\mathrm{m}]$

$D_{C . . .}$ diffusion coefficient related to the concentration difference [m/s]

$D_{D \ldots} \ldots$ pressure diffusion coefficient related to the difference of partial pressures $[\mathrm{kg} /(\mathrm{m} \cdot \mathrm{s} \cdot \mathrm{Pa})]$

Due to the fact that the concentrations are consistent with density $(c \equiv \rho), \rho$ the expression of an ideal gas equation and substituting into the relationship Fick law (1.1) is valid $D_{c}=r \cdot T \cdot D_{D}$. Because the value $D_{C}$ for air and water vapour is equal to the ratio of $D_{D P}=r_{v} / r_{p}=0,622$ to determine the relationship:

$$
D_{C}=\frac{2,194}{p_{b}} \cdot \frac{T^{1,8}}{273^{1,8}}=90,395 \cdot 10^{-5} \cdot \frac{T^{1,8}}{p_{b}}\left[\mathrm{~m}^{2} / \mathrm{s}\right]
$$

Fick's law is valid for double diffusion, which usually does not occur. Water vapour can diffuse from the water into the air without barriers, but air can't diffuse to water level. Water vapour molecules can diffuse from the surface into the air and also air molecules can diffuse towards the surface. However air molecules reach only the surface of the non-changing levels, where clump together and they saturate with water vapour and by convective motion are returning back. With water vapour movement increases the flow of molecules that can diffuse in the air. Mass flow of water vapour is so bigger with one-sided diffusion than double. Correcting for the flow of evaporating moisture is known as Stefan's correction for one-sided diffusion.

Moisture transfer happens in most cases as the diffusion water vapour from the water into the air, but there are cases where there may be an inverse gradient diffusion of water vapour. The direction of mass flow of steam is defined by each physical and psychrometric quantities of water and air.

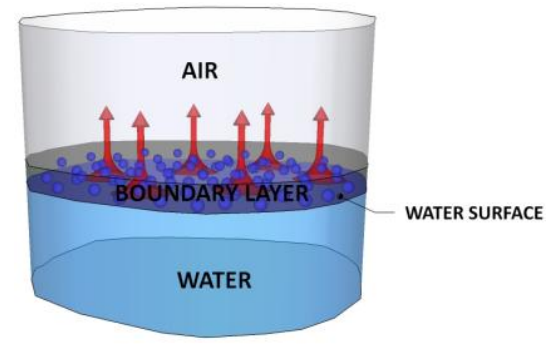

Figure 1: Illustration of the principle of water evaporation 


\section{The theory of heat and mass transfer between water surface and air}

The transmission of sensible heat by convection from the water's surface $S_{s}\left[\mathrm{~m}^{2}\right]$ and water's temperature $t_{w}\left[{ }^{\circ} \mathrm{C}\right]$ to the air with a temperature $t_{a}\left[{ }^{\circ} \mathrm{C}\right]$ describes the relation:

$$
Q_{c}=\alpha \cdot S_{s} \cdot\left(t_{w}-t_{a}\right) \quad[\mathrm{W}]
$$

where, $\quad \alpha \ldots . . .$. heat transfer coefficient between water surface and air

Convective flow of water vapour to the air from the surface describes the equation:

$$
\begin{aligned}
& m_{p}=\beta_{p} \cdot \Delta p_{p} \cdot S_{s} \cdot=\beta_{p} \cdot\left(p_{p s}^{\prime \prime}-p_{p}\right) \cdot S_{s} \quad[\mathrm{~g} / \mathrm{s}] \\
& m_{p}=\beta_{x} \cdot \Delta x \cdot S_{s}=\beta_{x} \cdot\left(x_{s}^{\prime \prime}-x\right) \cdot S_{s} \quad[\mathrm{~g} / \mathrm{s}]
\end{aligned}
$$

where, $\beta_{p}$....moisture transfer coefficient related to the differences of partial pressure of saturated water vapour just above the water and water vapour in the ambient air $\left[\mathrm{g} /\left(\mathrm{m}^{2} \cdot \mathrm{Pa}\right)\right]$

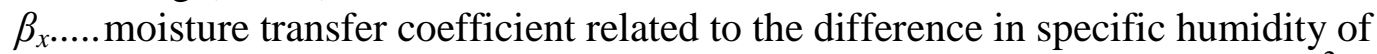
saturated air just above the water (at surface and air in the vicinity) $\left[\mathrm{g} /\left(\mathrm{m}^{2} . \mathrm{s}\right)\right]$

$p_{p s}^{\prime \prime . ~}$.pressure of saturated water vapour $[\mathrm{Pa}]$

$p_{p} \ldots$ pressure of saturated water vapour $[\mathrm{Pa}]$

$x_{s}^{\prime \prime} \ldots$ specific humidity $[\mathrm{kg} / \mathrm{kg}]$ in the ambient air for temperature $t_{s}\left[{ }^{\circ} \mathrm{C}\right]$

$x$.....specific humidity $[\mathrm{kg} / \mathrm{kg}]$ in the ambient air for temperature $t_{a}\left[{ }^{\circ} \mathrm{C}\right]$

\section{Application of the theory and implementation of calculation}

A major challenge in the practical calculation is to determine the heat transfer coefficient and substance, bound heat transfer coefficient in the boundary layer above the water and energy and psychrometric quantities of air and water in different layers. All these quantities are dependent on the basic boundary conditions of the calculation. These are:

$$
\begin{array}{ll}
\text { for air: } & \text { - indoor air temperature }\left[{ }^{\circ} \mathrm{C}\right] \\
& \text { - relative humidity of indoor air }[\%] \\
\text { for water: } & \text { - air velocity above the surface }[\mathrm{m} / \mathrm{s}] \\
& \text { - the water temperature }\left[{ }^{\circ} \mathrm{C}\right]
\end{array}
$$

For these boundary conditions can be calculated to determine other parameters of the state of the air both indoors and in the boundary layer above the surface. These include:

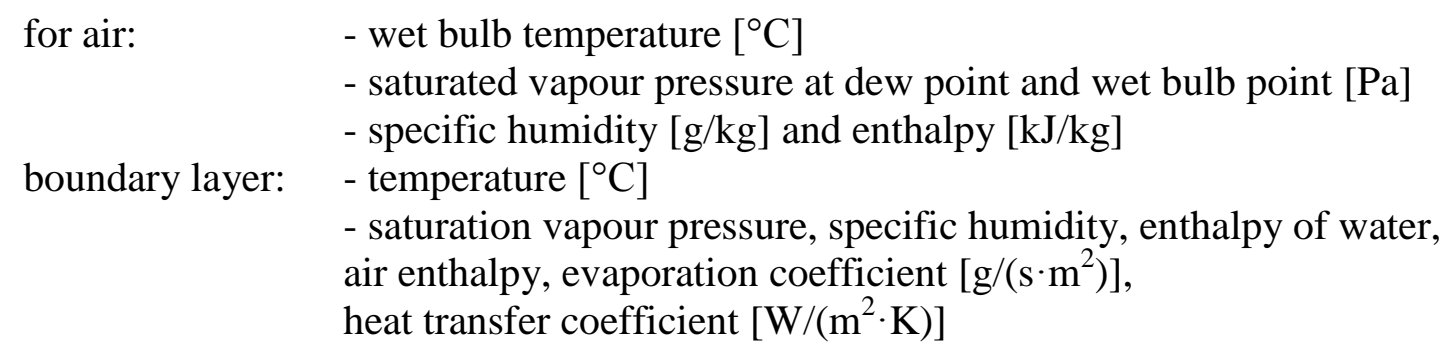


Based on the variables determining physical conditions in the boundary layer and the application of Fick law is possible to calculate the individual flows of heat and mass flow of water.

\section{Results}

Computer modelling entails the possibility of rapidly testing the effects of selected parameters on the behaviour of the monitored system. In the case of transfer of moisture in the pool hall are interesting this dependencies:

- quantity of evaporated water at the temperature of the interior

- quantity of evaporated water at the relative humidity in the interior

- heat flow on the temperature of the interior

Examination of dependence is a simple sensitivity analysis, which allows a good understanding of monitored phenomena. The calculation included the procedures for determining the mass flow through various methods.

\section{Dependence quantity of evaporated water on the interior temperature}

For the modelling of evaporation depending on the temperature of the interior boundary conditions were chosen to suit the physiological perception of the hydrothermal microclimate by human in a confined space (heat without stuffiness). As a relative humidity of the interior was chosen $55 \%$ humidity, air flow over the surface of $0,15 \mathrm{~m} / \mathrm{s}$, this is the speed of air, that occurs when a person is floating. The water temperature was selected $26{ }^{\circ} \mathrm{C}$. The results are shown in the graph in Figure 2.

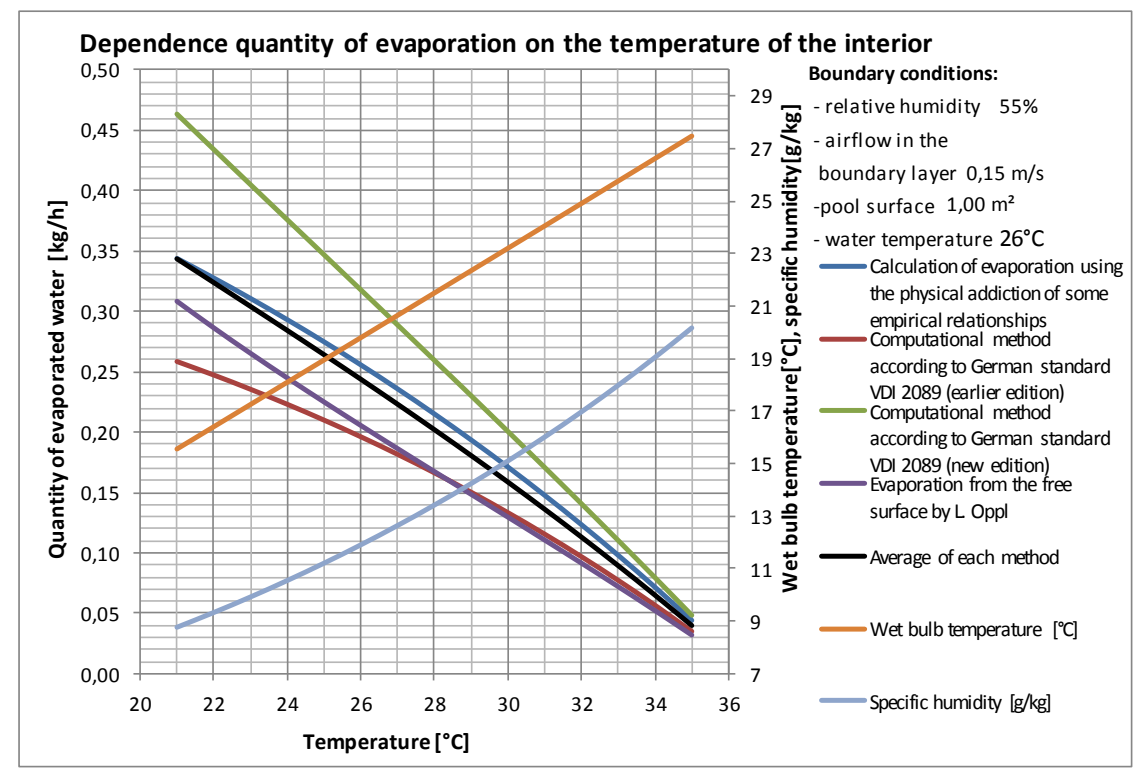

Figure 2: Graph quantity of evaporated water depending on the temperature of the interior

The graph shows less evaporation at higher air temperatures when the wet bulb temperature and specific humidity is already so high that the diffusion of water vapour does not take place 
so intensely as at lower temperatures when the air is drier and the interior can accommodate more water vapour. Assuming the maintenance of a constant relative humidity is therefore advisable to choose a higher air temperature, because with increasing temperature reduces the amount of evaporated water and the claims for dehumidification.

\section{Dependence of evaporation on the relative humidity in the interior}

In this case were boundary conditions chosen so that the reverse diffusion of water vapour maybe also apparent. The temperature of pool water was chosen as the most frequently used in practice for small family pools is $26^{\circ} \mathrm{C}$, air flow over the surface is $0,15 \mathrm{~m} / \mathrm{s}$. The results are shown in the graph in Figure 3.

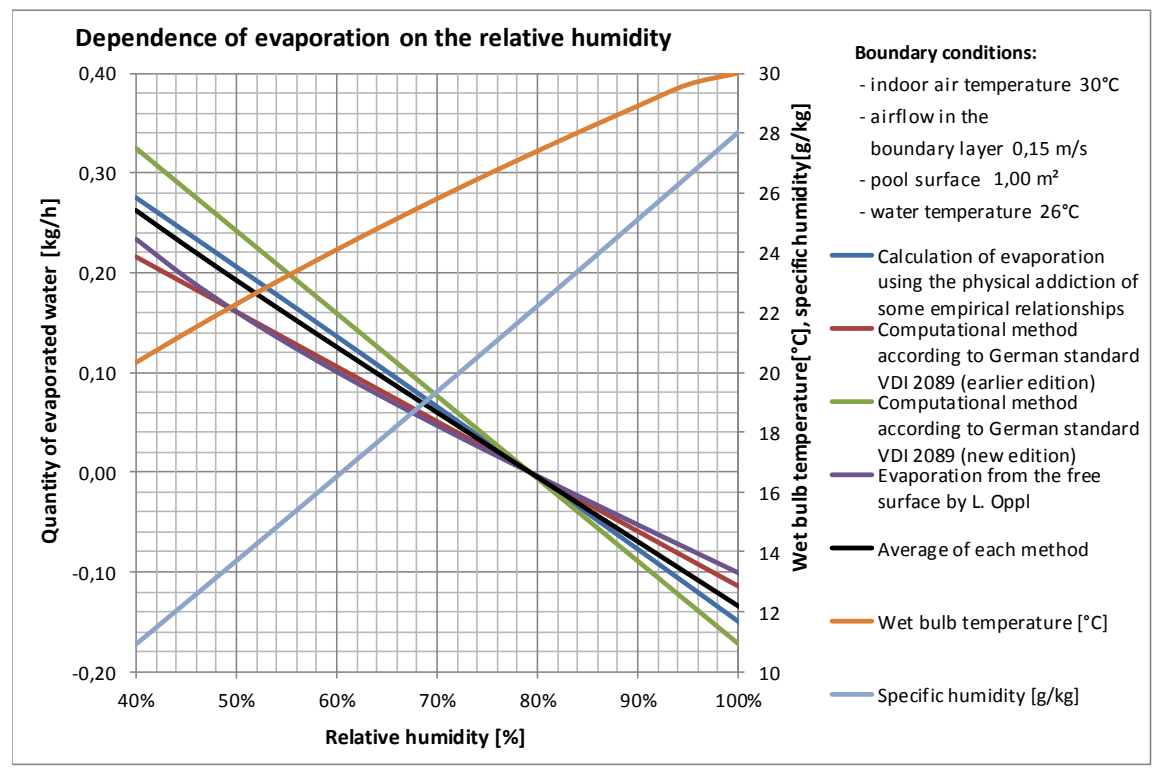

Figure 3: Graph quantity of dependence of evaporated water on the relative humidity in the interior.

In the graph is evident point where begins reverse diffusion of water vapour for specified conditions of air $30{ }^{\circ} \mathrm{C} / 80 \%$. When is the relative humidity higher than $80 \%$, there is no water evaporation from the pool, but the condensation of water vapour in the boundary layer at the surface of the pool.

\section{The dependence of heat flow on the temperature of the interior}

In this case, were chosen the same boundary conditions as in the evaporation depending on the temperature of the interior, the pool water temperature $26{ }^{\circ} \mathrm{C}$. The results are shown in the graph in Figure 4. 


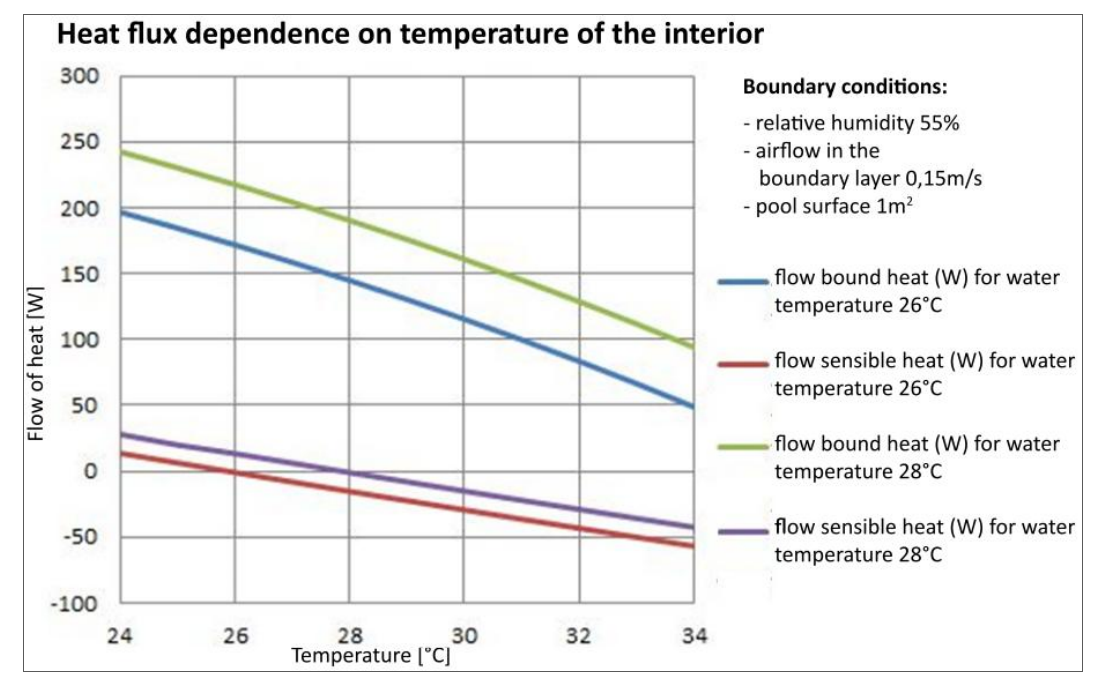

Figure 4: Heat flow depending on the temperature of the interior

The graph shows that are possible for the flow of sensible heat based on water temperature and the temperature of the interior under the given boundary conditions expect not only transfer sensible heat from the pool water to the air, but also vice versa. For bound heat it doesn't apply under the given conditions. Once again, it turns out that with higher air specific humidity (in the case of the same relative humidity of the air is warmer) leads to less diffusion of water vapour from the pool to the air above the water than in lower air temperatures.

\section{Optimization of the proposal in terms of energy consumption of air conditioning equipment}

Solving design optimization is processed in the simulation software TERUNA, which was designed for modelling various boundary conditions, which affect their own design. The program includes a module called "pools". The module consists of calculating evaporation from the surface. This corresponds to the algorithm that was used in a method called on the figure 2 and figure 3: Calculation of evaporation using the physical addiction of some empirical relationships, which appears to be given the evaporation during the middle of the curve in these graphs optimally. The second part of the module, which is shown in figure 5 is formed by a separate solution composition and design, including air conditioning units thermodynamic air editing. 


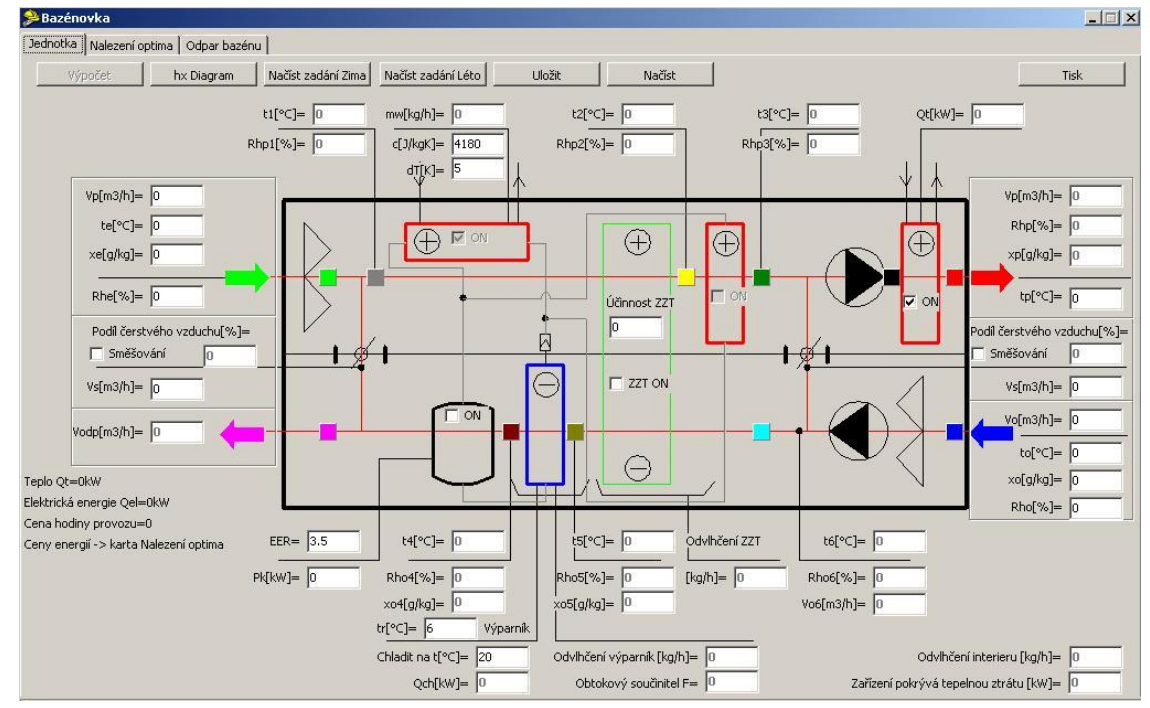

Figure 5: The computational model units designed for controlled year-round dehumidification

The third part consists of the software module optimization, it choose the most suitable combination of thermodynamic changes that we have with regard to the smallest total energy consumption. In this section you can make a proposal to extreme climatic conditions in the exterior of the building in summer and winter. However, software also allows you to specify own boundary conditions describing the transition period when the outdoor climatic conditions are very unfavourable for drying (wet autumn, after the rain, etc.). Based on the given boundary conditions have multiple iterative calculation and set individual inputs and outputs of individual elements, so that if the laws of physics allow, maintain required environmental parameters in the interior while also respecting minimize operational costs. Price of energy (heat and electricity) is entered on this tab, the calculation module.

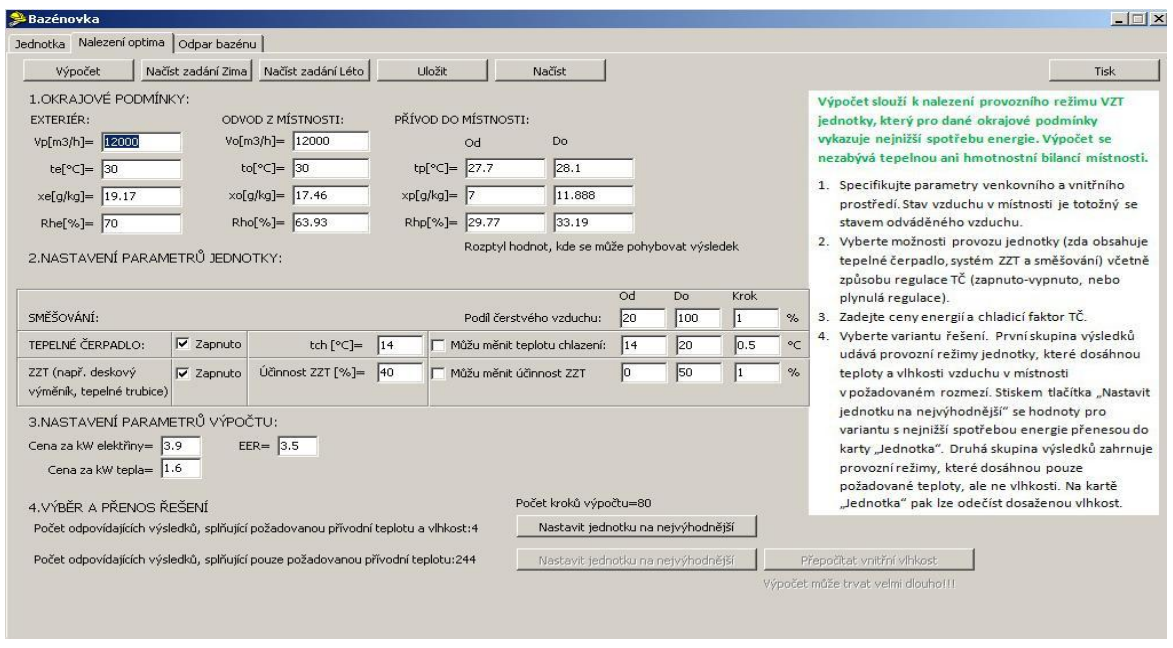

Figure 6: Sample module for the optimization calculations 


\section{Conclusion}

With today's computer modelling capabilities we can simulate different states of air and water, and examine the fundamental physical phenomena such as evaporation of water. Article points out the complexity of the physical problem and offers a complete solution for certain simplifications using the newly developed computational module. The individual graphs are apparent evaporation depending on the individual physical and psychrometric quantities. Understanding of the processes taking place during water evaporation from the surface it is possible to ensure optimal processing procedure for engineering design of the ventilation systems serving these areas.

The article was written with the support of specific research at the Brno University of technology, Faculty of civil engineering.

\section{References}

[1] HEMZAL, K. (2004). Přenosové jevy v technice prostředí. vyd. 1. Place of publication: Praha, Publisher: ČVUT. ISBN 978-800-1029-244.

[2] JíCHA, M. (2001). Přenos tepla a látky. 1. vyd. Place of publication: Brno, Publisher: CERM. ISBN 80-214-2029-4.

[3] RUBINA, A, TESA ̌̌, Z \& BLASINSKI, P. (28.11.2011). Modelování fyzikálních jevů 1 - Odpar $\mathrm{z}$ vodní hladiny. Retrieved date of access 22.5.2012. From URL: http://vetrani.tzb-info.cz/8076-modelovani-fyzikalnich-jevu-1-odpar-z-vodni-hladiny

[4] RUBINA, A. TESAŘ, Z. \& RUBINOVÁ, O. (2010). Software TERUNA v1.5 Modul pro odpar vody $\mathrm{z}$ hladiny a návrh bazénových jednotek. Retrieved date of access 22.5.2012. From URL: http://www.technikabudov.cz/tep_chovani.htm

[5] BLASINSKI, P. (2011). Vlhkostní bilance bytu. Place of publication: Brno. Publisher: Brno University of technology, Department of building services.

[6] RUBINA, A. TESǍ̌, Z. \& RUBINOVÁ, O. (2012), TERUNA ver. 1.5b [computer sofware]. The location: www.technikabudov.cz/software 